\title{
From indecision to precision: advances in imaging in metastatic prostate cancer
}

\author{
D. Bolton ${ }^{1} \cdot$ M. Frydenberg ${ }^{2}$
}

Published online: 28 May 2019

○) Springer-Verlag GmbH Germany, part of Springer Nature 2019

There can be little doubt that advances in medical imaging have had the greatest influence on prostate cancer management, since the identification of PSA and its use as the dominant serum biomarker for prostate cancer. Currently available imaging formats using MRI and PET technology have become incorporated into the treatment algorithm for prostate cancer in a manner that could not have been conceived in the early phase of this current era of prostate cancer treatment.

This topic issue seeks to exemplify how the utility of prostate cancer imaging may be further extended. From the role of MRI in determining approaches to detection of locally advanced disease $[1,2]$ and management of extracapsular extension [3], the urologist is now able to individualise surgical therapy with a view to optimising the likelihood of local disease control being achieved surgically with minimal comorbidity.

In distant metastatic disease and recurrent cancer PSMA PET scanning in its multiple forms also now offers clinicians the opportunity to determine the locality and extent of advanced disease in a manner that similarly permits the tailoring of therapy to reduce cost and morbidity [4]. The likelihood exists that over time these technologies will further inform refinements to contemporary practice in a way that specifically tailors the use of androgen deprivation therapy, immunotherapy and cytotoxic agents to each patient's needs, in contradistinction to the one-size-fits-all approach that has existed to date [5]. An opportunity exists also for urologists to again become the drivers of management in advanced cancer by means of the use of theranostics to this advantage [6].

D. Bolton

damienmbolton@gmail.com

1 Department of Urology, Olivia Newton-John Cancer Wellness and Research Centre, University of Melbourne, Austin Health, Heidelberg 3084, Australia

2 Department of Surgery, Monash University, Clayton 3168, Australia
A common theme of the manuscripts from Europe, North America and Australasia in this topic issue is that research in this area may be driven by urologists, rather than by medical imaging clinicians. This is something to be applauded and encouraged, and it obliges all urologists who practice in the area of prostate cancer to be apprised of the current status of these technologies. In doing so, management of patients with potentially advanced and recurrent prostate cancer may be optimised, and the boundaries of such improvements in care further extended.

\section{References}

1. Marenco J, Orczyk C, Collins T, Moore C, Emberton M (2019) Role of MRI in planning radical prostatectomy: what is the added value? World J Urol. https://doi.org/10.1007/s00345-019-02762-2

2. Pokorny M, Kua B, Esler R, Yaxley J, Samaratunga H, Dunglison N, Gianduzzo T, Coughlin G, Holt R, Laing B, Ault D, Brown N, Parkinson R, Thompson L (2018) MRI-guided in-bore biopsy for prostate cancer: what does the evidence say? A case series of 554 patients and a review of the current literature. World J Urol. https ://doi.org/10.1007/s00345-018-2497-y

3. Duncan C, Joon DL, Lawrentschuk N, Jenkins T, Schneider M, Khoo V, Chao M, Lawlor M, O'Meara R, Berry C, Viotto A, Brown K, Wada M, Foroudi F, Sengupta S (2018) Fiducial markers: can the urologist do better? World J Urol. https://doi. org/10.1007/s00345-018-2515-0

4. Sathianathen NJ, Butaney M, Konety BR (2018) The utility of PET-based imaging for prostate cancer biochemical recurrence: a systematic review and meta-analysis. World J Urol. https://doi. org/10.1007/s00345-018-2403-7

5. Fankhauser CD, Poyet C, Kroeze SGC, Kranzbühler B, Schüler HIG, Guckenberger M, Kaufmann PA, Hermanns T, Burger IA (2019) Current and potential future role of PSMA-PET in patients with castration-resistant prostate cancer. World J Urol 37(3):457467. https://doi.org/10.1007/s00345-018-2408-2

6. Eapen RS, Nzenza TC, Murphy DG, Hofman M, Cooperberg M, Lawrentschuk N (2018) PSMA PET applications in the prostate cancer journey: from diagnosis to theranostics. World J Urol. https ://doi.org/10.1007/s00345-018-2524-z

Publisher's Note Springer Nature remains neutral with regard to jurisdictional claims in published maps and institutional affiliations. 